\title{
Response to: The necessity for spirometry in the primary care management of COPD
}

\author{
Patrick White
}

Department of General Practice \& Primary Care, Guy's, King's \& St Thomas' School of Medicine, King's College London and General Practitioner, Crowndale Medical Centre, London SE19 3NY, UK

\author{
KEYWORDS \\ Spirometry; \\ COPD; \\ Primary Care; \\ Chronic obstructive \\ pulmonary disease
}

The case for the widespread adoption of spirometry in primary care put by Niels Chavannes is based almost solely on the role of spirometry in the detection of COPD at an early stage in the disease. Early detection of COPD should lead to the possibility of promoting smoking cessation in smokers with COPD. Smoking cessation is the great challenge in COPD. Anything that increases smoking cessation rates is to be recommended. This is essentially an argument for the role of screening with spirometry in the secondary prevention of COPD [1].

The case for screening for COPD in primary care should be determined ultimately by the advantage offered to patients who are identified from the screening process [2]. It requires an analysis of the number of cases detected by screening in whom the development of COPD can be arrested by a smoking cessation intervention. It demands a clear plan on how a screening programme in primary care can be implemented. Evidence to enable all of these conditions to be addressed is not yet available, but the argument is compelling for those primary care teams which are motivated to use spirometry as a screening tool now. Interest-

E-mail address: patrick.white@kcl.ac.uk (P. White). ingly, the paper quoted by Chavannes to support his statement that spirometry is "proven to be a helpful tool in convincing patients to stop smoking", shows that there is no difference in the cessation rate of subjects with normal lung function compared to those with abnormal lung function and suggests the opposite of his conclusion [3].

Chavannes argues that primary care has the capacity to do spirometry as well as it is done in hospital. This is not surprising particularly with modern hand-held electronic spirometers which can be set to accept spirometric readings only if the subject achieves the ATS criteria of three readings with an $\mathrm{FEV}_{1}$ within $0.2 \mathrm{l}$ of each other [4]. Spirometry is a relatively simple test. It requires careful instruction of the patient, three acceptable tests, regular calibration of the instrument, and regular in-service training of the operator. Its principal drawback is that it is time consuming to conduct reliably. In addition, it requires technical expertise to interpret and it is unlikely to be needed often enough in day-to-day consulting to justify every GP and practice nurse becoming proficient in its use. It is likely to remain a test that is done outside the routine consultation.

The role of lung function in the primary care management of COPD is complex at every stage of the disease, and not just in screening. The approach to 
lung function in COPD management is demanding whether it is in the diagnosis of the disease, the treatment of the symptoms, the management of exacerbations, or the interventions that are made to prevent or shorten the length of hospital admissions. None of these issues is addressed by Chavannes although he mentions in passing the role of spirometry in diagnosis and monitoring.

The management of COPD is undergoing a radical shift. From a relatively nihilistic position in the late 1990s when the only invention thought likely to influence the outcome of the disease was smoking cessation, the approach of clinicians and researchers in COPD is changing. In the early stages of the disease asthma and COPD may co-exist and the airways obstruction may have a significant reversible component. Later in the disease when reversibility appears to have been all but lost clinical improvement can still be gained with long acting inhaled anti-cholinergics (tiotropium), with long acting beta-agonists (salmeterol and formoterol) and with oral steroids [5-7]. The impact of these changes though small is significant and worth seeking. The effects of the drugs are subtle. They influence the frequency of exacerbations as well as symptoms. They also improve lung function. Lung function also deteriorates in acute exacerbations and improves with recovery.

There are advantages to measuring lung function in severe COPD. The measurement gives doctor and patient an objective view of what is happening which they can share. Small changes encourage patient and doctor to continue with their strategy. The absence of change after a new treatment may convince patients and doctors that the intervention has little to offer. These measurements should form part of the routine dialogue around the disease upon which the treatment (including smoking cessation) is set. Spirometry is useful for this purpose every $1-2$ years. It will only be used within the consultation by enthusiasts who are happy to borrow the time from other consultations. When it comes to the annual or biennial test, where it is done and how is less important than that it is done well. In the meantime, the less complete measure of lung function, peak expiratory flow (PEF), should help to fill the gap. PEF measures airway calibre which is the element of lung function which the drugs are designed to improve, and which gets worse during exacerbations. It tells us little about the underlying structural damage caused by the disease but that detail can be provided every 1-2 years by spirometry. Lung function measurement is not a substitute for the detailed clinical assessment and advice needed by COPD sufferers but it provides a useful backdrop to the consultation and helps to anchor it in the underlying process of the disease.

\section{References}

[1] Chavannes N. The necessity for spirometry in the primary care management of COPD. Prim Care Respir J 2004;13(1): $11-4$.

[2] Wilson JM. Principles of screening for disease. Proc R Soc Med 1971;64(12):1255-6.

[3] Gorecka D, Bednarek M, Nowinski A, Puscinska E, GoljanGeremek A, Zietinski J. Diagnosis of airflow limitation combined with smoking cessation advice increases stop-smoking rate. Chest 2003;123(6):1916-23.

[4] Committee on Proficiency Standards for Clinical Pulmonary Function Laboratories, American Thoracic Society. Standardization of Spirometry. Am J Respir Crit Care Med 1995;152: 1107-36.

[5] Casaburi R, Mahler DA, Jones PW, Wanner A, San PG, ZuWallack RL, et al. A long-term evaluation of once-daily inhaled tiotropium in chronic obstructive pulmonary disease. Eur Respir J 2002;19(2):217-24.

[6] Calverley P, Pauwels R, Vestbo J, Jones P, Pride N, Gulsvik A, et al. Combined salmeterol and fluticasone in the treatment of chronic obstructive pulmonary disease: a randomised controlled trial. Lancet 2003;361(9356):449-56.

[7] Irwin RS, Madison JM. Systemic corticosteroids for acute exacerbations of chronic obstructive pulmonary disease. $\mathrm{N}$ Engl J Med 2003;348(26):2679-81.

Available online at www.sciencedirect.com

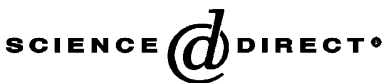

